\title{
AVALIAÇÃO DOS CRITÉRIOS MORFODINÂMICOS PARA A FASE DE DIAGNÓSTICO DO PROJETO ORLA: UM ESTUDO DE CASO EM PRAIAS ARENOSAS COM DESEMBOCADURAS FLUVIAIS
}

\section{Evaluation of the morphodynamic criteria for the diagnostic phase of Projeto Orla: a case study on sandy beaches with river mouths}

Thaís Baptista da Rocha

Doutoranda em Geografia, UFRJ. Bolsista CAPES thaisitc5@yahoo.com.br

Guilherme Borges Fernandez Prof. Adjunto, Depto. de Geografia, UFF

Lidice Cabral Nascimento

Doutoranda em Geografia, UFRJ. Bolsista CAPES

lidicecabral@yahoo.com.br

Artigo recebido em 04/06/2012 e aprovado para publicação em 06/12/2012

RESUMO: O presente trabalho buscou analisar parte dos critérios de diagnóstico do Projeto de Gestão Integrada da Orla Marítima (Projeto Orla) do Ministério do Meio Ambiente (2002), especificamente considerando a morfodinâmica e a fisiografia, como justificativa para a uma análise voltada para a vulnerabilidade física. Logo, buscou-se a realização deste trabalho na orla próximo à foz do rio Paraíba do Sul, cuja área é reconhecida pela intensa instabilidade morfológica e fases severas de erosão costeira. Foi averiguada a metodologia de delimitação da orla propriamente dita, o estabelecimento de áreas restritivas ou de não-edificação e a caracterização de tipologias de orla, associada ao estabelecimento de Unidades de Paisagem. A aplicação prática de tais critérios indicou algumas fragilidades e a necessidade de adaptações às características geomorfológicas da orla. Desta forma, foram sintetizadas sugestões de adaptação e complementação, como por exemplo, a aplicação de Geoindicadores para avaliação do comportamento morfodinâmico da orla.

Palavras-chaves: Projeto Orla, Morfodinâmica Costeira, Diagnóstico Paisagístico, Geoindicadores.

ABSTRACT: The aim of this study is to analyze part of diagnostic criteria of the integrated coastal management project (Projeto Orla), specifically considering the morphodynamics and physiography as justification for an analysis focused on the physical vulnerability. Therefore, this work was carried out on the coast area close to the mouth of the Paraiba do Sul River, whose area is recognized by the intense instability and morphological stages of severe coastal erosion. The methodology for delineation of the shore, the establishment of restricted or non-building areas and characterization of shore types, associated with the establishment of Landscape Units were investigated. The application of these criteria indicated some weaknesses warning for the need of some adaptations related to the geomorphological characteristics of the coast. Thus, suggestions were synthesized for adapting and complementing, for example, the application of geoindicators for performance evaluation of coast morphodynamic.

Key Words: Projeto Orla, Coastal morphodynamics, Landscape Diagnosis, Geoindicators 


\section{INTRODUÇÃO}

A orla marítima apareceu recentemente no Brasil como um espaço prioritário às ações voltadas ao ordenamento da ocupação e uso do solo, e como espaço estratégico ao gerenciamento costeiro, necessitando de diretrizes à preservação e conservação ambiental, a partir da formulação do Plano de Ação Federal para a Zona Costeira no ano de 1998. De acordo com Moraes (2009), o amadurecimento dos propósitos do Programa Nacional de Gerenciamento Costeiro (PNGC) permitiu perceber a necessidade de se trabalhar paralelamente com um espaço de maior detalhe no ordenamento territorial litorâneo, remetendo para o lugar imediato de contato entre os meios aquáticos e terrestres, abarcando fenômenos intra-urbanos e intramunicipais.

As bases para o ordenamento deste espaço encontram-se instrumentalizadas no Projeto de Gestão Integrada da Orla (Projeto Orla, que inclui os ministérios do meio ambiente e do planejamento, orçamento e gestão) amparado pelo decreto 5.300 de 2004, que regulamenta a lei 7.661 de 1988 . O programa tem basicamente o objetivo de propor e aplicar diretrizes gerais de disciplinamento de uso e ocupação da orla, considerando aspectos de gestão patrimonial e ambiental, com finalidades como a valorização da paisagem, valorização de atrativos turísticos, reversão de processos de degradação, utilização sustentável da biodiversidade, entre outros.

Visando um diagnóstico e posteriormente um Plano de Intervenção, a metodologia desenvolvida para a execução do Programa foi dividida em cinco fases: Instrumentalização, Aplicação Prática, Consolidação, Planejamento das Ações Locais e Implementação. Tal organização envolve um conjunto específico de atividades, responsabilidades e produtos. Em geral, a fase de Instrumentalização está voltada para a fase de organização e integração de materiais e dados disponíveis sobre o município, podendo ser aprofundado os conceitos e fundamentos do Projeto Orla. A Aplicação Prática traz orientações para a elaboração do diagnóstico, classificação e definição de cenários de usos e ocupação da orla do município. A terceira fase refere-se à Consolidação das informações apreendidas nas fases anteriores por um grupo técnico.
No Planejamento das Ações Locais, é apresentado um roteiro para a elaboração do plano de intervenção, para então haver a Implementação das ações por uma coordenação local.

Moraes e Zamboni (2004) chamam atenção para a construção do nome que designasse essa porção mais restrita da zona costeira, optando-se por utilizar o termo orla marítima. De acordo com o próprio Programa, este espaço é definido como uma unidade geográfica inclusa na zona costeira, delimitada pela faixa de interface entre a terra firme e o mar, cujo ambiente é caracterizado pelo equilíbrio morfodinâmico. Desta forma, os processos geológicos e oceanográficos têm importância no comportamento e evolução desses ambientes, além de configurar diversos tipos de orla como falésias, praias arenosas, planícies lamosas, manguezais entre outros. Neste sentido tais aspectos aparecem como pertinentes à avaliação de Diagnóstico da orla.

Os critérios e metodologias de avaliação e de diagnóstico referentes à consideração da geomorfologia e morfodinâmica costeira encontram-se no volume "Projeto Orla: Subsídios para um Projeto de Gestão" (MMA/SQA; MP/SQU, 2004), especificamente no capítulo "Definição de limites e tipologias da orla sob os aspectos morfodinâmicos e evolutivos" (MUEHE, 2004). Além disto, no volume "Projeto Orla: Fundamentos para Gestão Integrada" (MMA/SQA; MP/ SQU, 2002), encontram-se atividades envolvendo a identificação de elementos da paisagem local, apresentação de critérios para delimitação de orla, e demarcação de trechos com homogeneidade paisagística (tipologias de orla). Cabe ressaltar que tais atividades encontram-se inter-relacionadas em tais publicações.

Desta forma, o objetivo do presente trabalho é analisar parte destes critérios de diagnóstico de gestão de orla marítima, do ponto de vista morfodinâmico e fisiográfico. Para isto, a partir de um estudo de caso, buscou-se a realização deste trabalho na orla próximo á foz do rio Paraíba do Sul, localizado no município de São João da Barra, na região norte-fluminense, cuja área é reconhecida pela intensa instabilidade morfológica e por haver uma rede de monitoramento topobatimétrica de dinâmica costeira desde o ano de 2005, consolidada pela Universidade Federal Fluminense. 


\section{CRITÉRIOS MORFODINÂMICOS PARA O DIAGNÓSTICO DA ORLA MARÍTIMA}

\section{Delimitação da faixa de orla marítima e de áreas de não-edificação}

No Projeto Orla, o estabelecimento da faixa de orla marítima faz parte do escopo dos objetivos e produtos do Programa, conforme dispostas as diretrizes contidas na fase de Diagnóstico. Desta forma, cada município deve apresentar seus critérios para delimitação de orla e como produto, um mapa contendo tal faixa mapeada (MMA/SQA;MP/SQU, 2006).

Especificamente sobre os critérios gerais envolvendo esta delimitação, há certa incongruência no que é apresentado no volume "Projeto Orla: Fundamentos para Gestão Integrada" (2002) e na legislação sobre a gestão de orla marítima, no decreto 5.300 de 2004 . No primeiro, o critério para delimitação da faixa terrestre da orla aparece como sendo o alcance do processo morfodinâmico atual, sugerido por Muehe (2004). Desta forma, o limite seria a porção mais interiorizada da berma mais elevada, ou o reverso do cordão litorâneo, já que seria o limite da ação da transposição de ondas - overwash; e no caso de transporte eólico, o limite seria a base do flanco reverso do campo de dunas frontais. A esses limites, seriam acrescidos 50 metros em direção a retroterra para áreas urbanizadas e 200 metros para áreas não-urbanizadas, conforme mostra a figura 1 . Neste volume, há também possíveis limites para demais ambientes como falésias, costões rochosos, manguezais, estuários e braços de mar.

Já no decreto, a linha de preamar (linha de alcance máximo da maré de sizígia) aparece como um dos possíveis limites, contrariando, desta forma, o critério do alcance do processo morfodinâmico atual e se assemelhando a definição dos terrenos de marinha (Figura 1), podendo representar uma redução da área destinada à gestão. Outro possível limite refere-se à demarcação do final da praia. Segundo a definição legal de 1988 (Art $10^{\circ}$ da lei 7.661/88) e a definições de Short (1999), estes limites da praia na faixa terrestre podem ser onde se inicie a vegetação natural, o início da ocorrência de dunas ou qualquer outra feição fisiográfica brusca. A todos estes limites devem ser acrescidos 50 metros ou 200 metros.

Figura 1: Delimitação da faixa de orla marítima, para o caso de orla urbanizada e não-urbanizada.

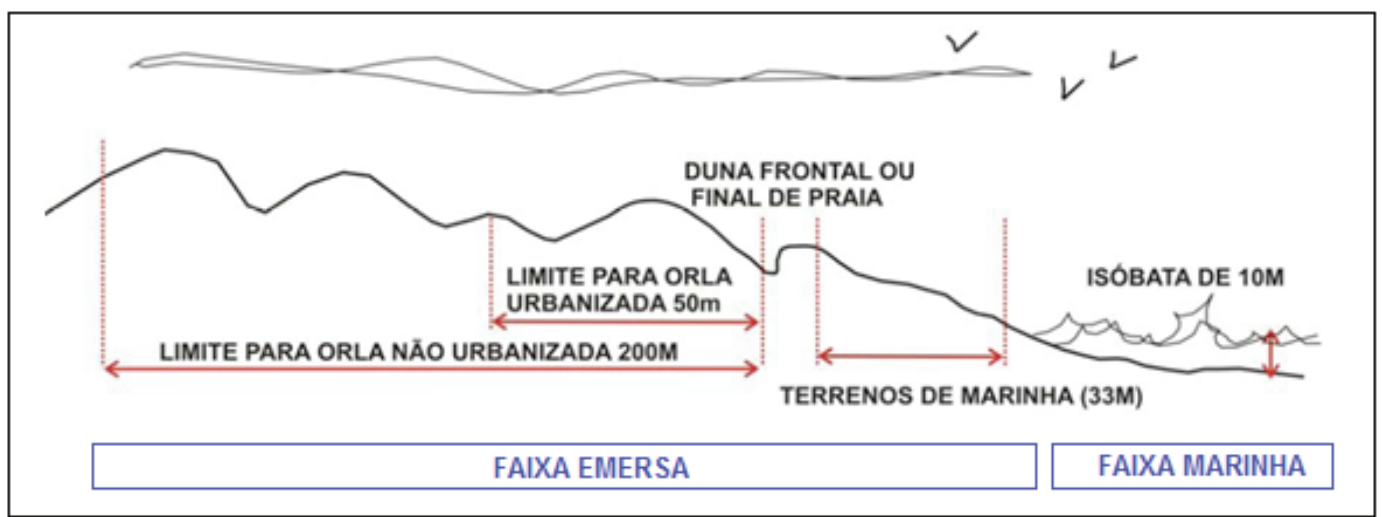

Fonte: Adapt. de MMA/SQA;MP/SQU, 2002.

Embora estes critérios e limites estejam destacados na legislação, não há referência à restrição de uso e ocupação, com a finalidade de configurar áreas restritivas ou de não-edificação. De acordo com Rufino (2004), a Noruega, em seu Act for planning on shore areas de 1971, confirmou a proibição geral de construções sobre faixa de $100 \mathrm{~m}$, assim como a Suécia e Dinamarca dispondo de limites similares. Nesta última, o princípio que proíbe a construção na faixa de 100m remonta aos anos 30. Já a Itália, em 1985 proíbe sobre faixa de $300 \mathrm{~m}$, medidos a partir do mar, toda modificação do ambiente fora das zonas urbanizadas. 
A Espanha, por exemplo, possui diretrizes de gestão de orla que datam de 1969. Nesta foi estipulado um limite máximo de orla de até $500 \mathrm{~m}$ e estipulado um limite de $100 \mathrm{~m}$ para faixas de não edificação, sendo proibidas nessa faixa edificações destinadas à residência, construções ou modificações de vias de transporte interurbano, entre outros

Apesar deste tipo de intervenção ser comum em muitos países, tal atividade aparece apenas como algo sugestivo no volume "Subsídios ao Projeto Orla". De acordo com a proposta de Muehe (2001 e 2004), os limites destas faixas de não-edificação seriam os mesmos apresentados para a delimitação da orla apresentada acima. Para o mesmo autor, uma vez que os limites dos terrenos de marinha (33 metros a partir da linha de preamar média de 1831), geralmente não chegam à berma da praia este não deveria ser mais mencionado como um possivel limite para qualquer medida de não edificação.

\section{Caracterização de tipologias de orla segundo crité- rios morfodinâmicos previstos no Projeto Orla e a metodologia do Diagnóstico Paisagístico}

No caso do Projeto Orla, uma de suas atividades envolve a formulação de critérios para avaliação da paisagem, em que são recomendáveis a demarcação de unidades de paisagem e a classificação em tipologias de orlas. Esta base metodológica do Programa é denominada "Diagnóstico Paisagístico". Este foi definido como instrumento que oferece um conjunto de conceitos e elementos que irão auxiliar a divisão da orla do município em trechos de homogeneidade paisagística, a partir de caracterizações rápidas e simplificadas.

Nesta metodologia, o conceito de Paisagem, aparece como fundamental, onde é avaliado como estrutura territorial dinâmica, resultado do processo de transformação do ambiente no decorrer do tempo sendo, desta forma, a unidade de paisagem o elemento de decodificação para o diagnóstico. Esta unidade, segundo o próprio programa, pode ser individualizada por uma homogeneidade resultante de um padrão urbanístico ou de um padrão natural, como um acidente topográfico ou tipo de vegetação, com uma escala de representação entre 1:25.000 e 1:10.000 (Figura 2a).
Na verdade, segundo Guerra e Marçal (2006), o dimensionamento da paisagem em unidades estaria relacionado à idéia da "Ecologia da Paisagem" definida por Carls Troll em 1950. De acordo com o autor, esta abordagem enfatiza a interação entre modelos espaciais e processos ecológicos, que é causa e conseqüência da heterogeneidade espacial, através do alcance da escala. Como metodologia, Troll (1997 apud GUERRA e MARÇAL, op.cit.) caracterizava a paisagem detectando e delimitando as suas diferenças para, em seguida, através de seu conteúdo e limites, chegar à compreensão da sua estrutura e classifica-la em diferentes escalas e territórios. Nesse sentido, podemos perceber a semelhança metodológica com a proposta pelo Projeto Orla, que parte das Unidades de Paisagem para chegar às tipologias.

De acordo com Moraes (2007), esta classificação tipológica deve buscar a setorização dos espaços pelo grau de similaridade, obtendo com isto o agrupamento dos lugares com características semelhantes. Em termos de gestão, isto se apresenta como uma ferramenta prática, uma vez que as ações de intervenção podem ser direcionadas de forma mais eficaz numa determinada área de planejamento.

No caso do Projeto Orla, inicialmente, o Programa sugere tipos genéricos de orla baseado em dois critérios, o de fisiografia e o de ocupação. $\mathrm{O}$ primeiro tem como objetivo indicar o grau de vulnerabilidade da orla face aos processos naturais e antrópicos; e o segundo, de verificar índices de ocupação humana e a intensidade de usos praticados.

Em relação à vulnerabilidade física, foco desta análise, as tipologias foram definidas em função do grau de exposição de ondas, o que resultou em tipos genéricos semelhante à metodologia trazida por Muehe (2001). A partir do grau de exposição à ação de ondas, a orla pode ser classificada em orla protegida, semi-exposta e exposta (figura $2 \mathrm{~b}$ ). Tais tipologias podem ser obtidas por simples caracterização visual ou pela aplicação do modelo de Wiegel (1974), conforme sugeriu Muehe (op.cit). Este último relaciona basicamente a declividade da face da praia e o grão médio dos sedimentos . 
Figura 2: 2A - Exemplo de Unidades de Paisagem da orla marítima (Adapt. MMA/SQA;MP/SQU, 2002, p 38). 2B - Tipologias de orla marítima

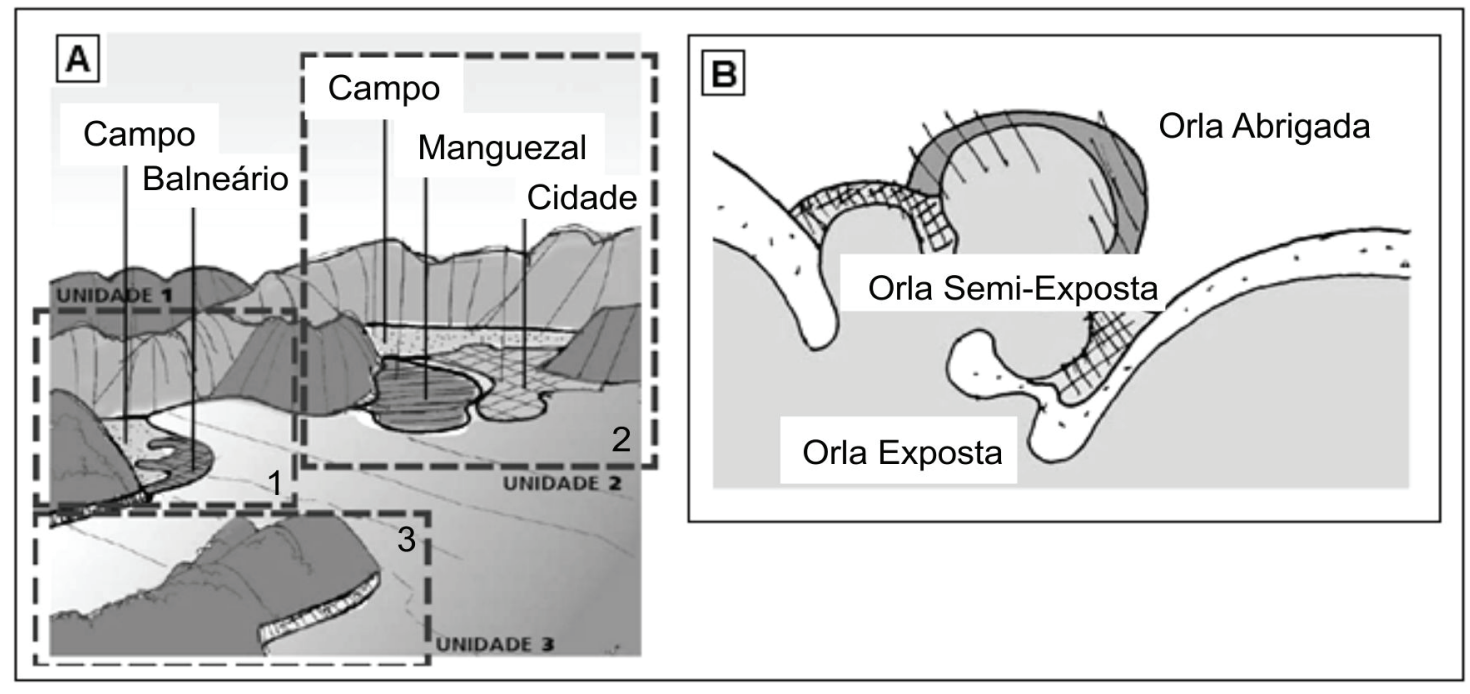

Fonte: Adaptado de MMA/SQA/MP/SQU, op.cit. p 32.

Esta classificação também visa agrupar algumas informações sobre a forma da orla, a posição e algumas características físicas, permitindo individualizar os tipos de formações costeiras como, por exemplo, baías, estuários e golfos como orlas abrigadas; praias oceânicas de baixa concavidade como orlas expostas; e as orlas semi-exposta, com características intermediárias das anteriores. Esta tipologia, inclusive, está amparada pelo Decreto 5.300/04 que estabelece os critérios de gestão da orla, especificamente na Seção dos Instrumentos, Art. 25 e 26.

\section{ESTUDO DE CASO: A ORLA MARÍTIMA NO MUNICÍPIO DE SÃO JOÃO DA BARRA (RJ)}

Aárea de estudo localiza-se no extremo Norte Fluminense, e abrange um litoral de aproximadamente 10 km, no município de São João da Barra, localizado na margem direita do delta do Rio Paraíba do Sul. (Figura 3).

As características geomorfológicas desta planície costeira estão predominantemente associadas à formação de cristas de praia (beach ridges) e também as dunas frontais. As primeiras são definidas como feições deposicionais arenosas, construídas por ação de ondas, podendo sofrer retrabalhamento eólico. São citadas como indicadores de antigas linhas de praia, associadas a posicionamentos pretéritos do nível do mar (OTVOS, 2000). Quando as cristas de praia apresentam-se consorciadas com dunas, também são conhecidas como Beach Foredune Ridge (HESP, 1999). Estas formações associadas a algumas lagunas e brejos, caracterizam uma das maiores áreas de restinga do litoral fluminense.

Em relação a morfodinâmica costeira, a área apresenta evidente instabilidade morfológica, sobretudo nas proximidades do desembocadura do Rio Paraíba do Sul. Os trabalhos mais recentes (BASTOS, 1997; FERNANDEZ et.al. 2006; ROCHA, 2009; SANTOS, 2006;) têm evidenciado um realinhamento da linha de costa, onde tem sido mapeada erosão costeira próximo à foz (Atafona) e progradação mais ao sul, na localidade de Grussaí (figura 3). Tal comportamento também tem refletido diretamente na dinâmica e morfologia das dunas frontais que tem resultado na constante migração das dunas sob as edificações.

Tais fatos têm representado um desafio para a população local, que constantemente tem sido obrigada a conviver com a perda material de seus imóveis, e também, para os gestores locais que se mostram à procura de soluções e ações de mitigação. Ainda assim o município não apresenta seu Projeto Orla implementado, embora tenha instituído seu Plano Diretor em 2006. No documento referente ao Diagnóstico de 
Plano Diretor do município, a localidade de Atafona foi reconhecida como área de risco, juntamente com outras áreas sujeitas à inundação atribuída às condições de drenagem local.

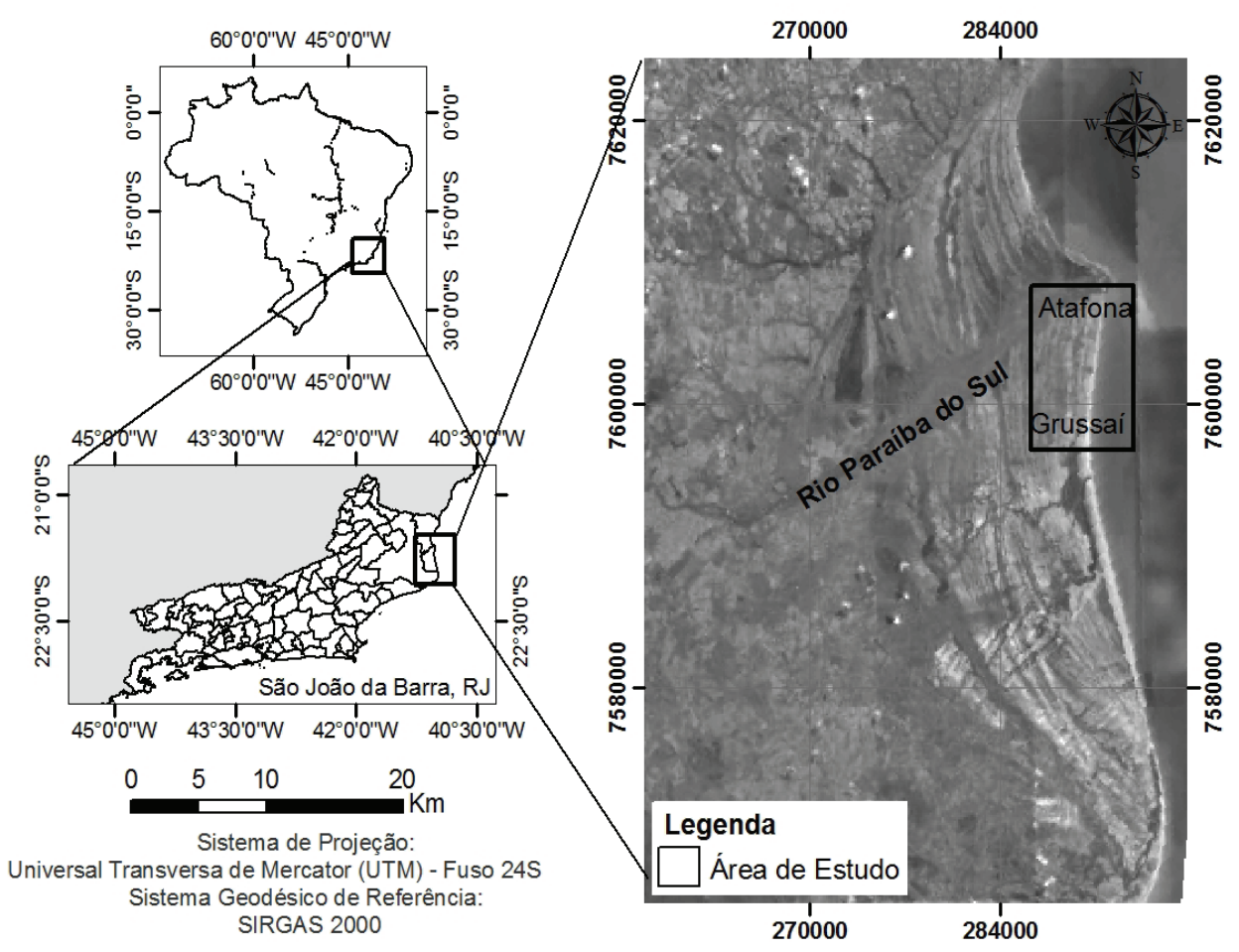

Fonte: Elaboração dos autores.

\section{METODOLOGIA}

Com o objetivo de verificar a viabilidade dos critérios fisiográficos e morfodinâmicos do Projeto Orla, foram averiguados a metodologia de delimitação de orla propriamente dita, o estabelecimento de áreas restritivas de caráter preventivo e/ou corretivo e a caracterização de tipologias de orla, associada ao estabelecimento de Unidades de Paisagem. Na verdade, esta análise está vinculada aos pontos de controle morfodinâmicos em São João da Barra, onde há um monitoramento sendo realizado desde 2005. Tais pontos podem ser visualizados na figura 4 .

No caso do estabelecimento da faixa de orla marítima foram considerados os critérios do Projeto Orla (limites de 50 e 200 metros) e foram utilizadas técnicas de mapeamento a partir de caminhamentos utilizando GPS (modelo GPSMAP 60 CSx), imagem de satélite ALOS do ano de 2008, na escala 1:25.000 e fotografias aéreas do ano de 1954 (escala 1:30.000), obtidas na Diretoria de Hidrografia e Navegação (DHN). Para o processamento dos dados, análises espaciais e confecção de mapas foi utilizado o aplicativo ArcGIS 9.3.

Especificamente para o mapeamento de possíveis áreas de não-edificação ou restrição utilizou-se o critério sugerido no volume "Subsídios ao Projeto Orla", de acordo com a proposta de Muehe (2004). Para o caso de orlas associadas à desembocaduras fluviais o autor sugere o estabelecimento da largura maior ou igual à foz, sendo esta transportada para o perímetro da parte oceânica da feição.

Já em relação ao Diagnóstico Paisagístico, procurou-se primeiramente setorizar as Unidades 
de Paisagem do trecho de orla estudado, a partir das características geomorfológicas e morfodinâmicas. Em seguida, a orla foi classificada nos dez pontos de controle morfodinâmico para a obtenção de tipologias de orla, baseado no critério do grau de exposição de ondas a partir de uma identificação visual, conforme é apresentado no Programa.

Para efeito de comparação com a metodologia das tipologias morfodinâmicas de orla, foi realizado um mapeamento através de Geoindicadores como proposta complementar à indicada no Projeto Orla. De acordo com a União Internacional de Ciências Geológicas (IUGS), os Geoindicadores são definidos como parâmetros de processos geológicos e de fenômenos que ocorrem na superfície terrestre, podendo gerar informações relativos à magnitude, freqüência, taxas e tendências, e com a finalidade de fornecer elementos para uma avaliação ambiental. São mais eficientes quando aplicados à escala de tempo de até 100 anos e numa escala espacial de paisagem $(0,1-10 \mathrm{~km})$ ou de meso-escala (10-100km). Os Geoindicadores geralmente visam às descrições do estado ambiental (SOE - state of environmental reporting), que são comuns na definição de elementos para estratégias de gerenciamento (BERGER, 1997; BUSH et.al., 1999).

No caso da identificação do estado ambiental de linhas de costa formadas de material inconsolidado, como praias arenosas, foram utilizados Geoindicadores baseado no trabalho de Bush et al. (op.cit), que chega a uma classificação de praias em Erosão Severa, Erosão ou Acreção/Estabilidade (tabela1).

Tabela 1: Tabela com Geoindicadores de avaliação de comportamento da linha de costa, com a respectiva numeração para posterior mapeamento. Fonte: Adapt. BUSH et al., 1999.

\section{EROSÃO SEVERA}

1 Ausência de dunas

2 Escarpa ativa por ondas

3 Canais de maré expostos

4 Ausência de vegetação

5 Presença de obras de engenharia

6 Escarpamento do pós-praia

\section{EROSÃO}

8 Dunas escarpadas ou rompidas

9 Escarpas íngreme e depósitos de tálus

10 Turfa, lama ou troncos expostos na praia

11 Berma estreita ou coberta por espraiamento

12 Presença de leques de transposição

\section{ACRESÇÃO / ESTABILIDADEE}

13 Dunas e cristas de praia bem vegetadas

14 Escarpa vegetada com rampa estável

15 Berma larga e bem desenvolvida

16 Ausência de leque de transposição

17 Vegetação de restinga bem desenvolvida

7 Presença de edificações ou estruturas danificadas 


\section{RESULTADOS}

\section{Delimitação das faixas de orla marítima e de faixas de uso restritivo}

Ao tentar estabelecer o critério para definir a faixa de orla, observou-se logo a dificuldade no tocante a fisiografia. Pretendia-se realizar tal levantamento a partir do reverso do cordão litorâneo mais frontal. Contudo, não foi possível visualizar tal reverso. Como a fisiografia se caracteriza pela formação de sucessivas cristas de praias, caracterizando uma área com topografia bastante suave, com topos de cristas de no máximo 4 metros em relação ao nível médio do mar, fica imperceptível a visualização do reverso dessas feições, salvo no pequeno trecho com dunas frontais alteadas, com cristas na ordem de 14 metros. Nesse sentido, optou-se por considerar o limite da vegetação e o do início das dunas, considerando serem estes os limites finais da praia.

A partir do arquivo vetorial em linha do caminhamento, foi aplicado o comando Buffer para delimitação de uma área obtida a partir da projeção de $200 \mathrm{~m}$ e $50 \mathrm{~m}$ em direção à retroterra, conforme estabelece o Programa no caso de orlas não urbanizadas e urbanizadas. Em ambos os casos gerou-se área contínua até o limite da batimétrica de 10 metros (figura 4).

Figura 4: Delimitação da faixa de orla marítima, para o caso de orla urbanizada e não-urbanizada.

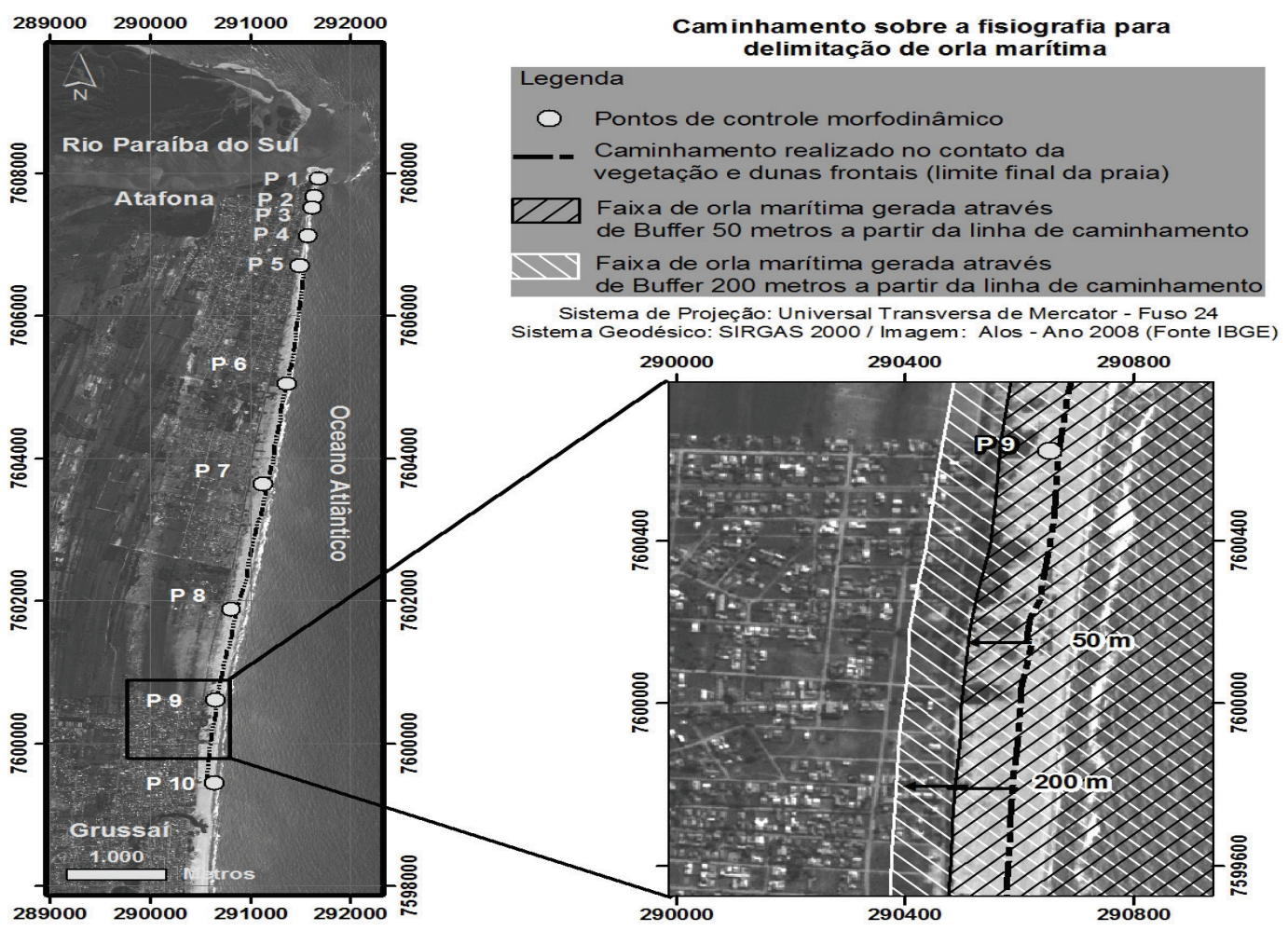

Elaboração dos autores.

Na verdade, optou-se por não entrar no mérito da discussão sobre o que seriam orlas urbanizadas e não urbanizadas, nem qual tipo se encaixaria na área apresentada. Mas sem dúvida a porção terrestre da orla de 50m apresenta-se bastante reduzida em comparação à orla de $200 \mathrm{~m}$. Em termos de área total, a diferença é aparentemente pouca, a primeira tem $22,22 \mathrm{~km}^{2}$ e a outra $23,72 \mathrm{~km}^{2}$. Porém, comparando apenas a parte terrestre, a diferença chega à aproximadamente $60 \%$ que, mais uma vez, pode representar uma perda significativa de área de abrangência para a gestão. 
No caso da delimitação de uma faixa de uso restrito, considerando os riscos associados à erosão na presente área, ao ser utilizado o critério do transporte da largura do canal fluvial, a primeira questão levantada refere-se à mudança morfológica que normalmente ocorre nos canais fluviais próximos à foz. $\mathrm{Na}$ presente área, por exemplo, os contornos foram largamente modificados durante as últimas décadas. Em 1954, um determinado ponto de largura da foz foi estimado em $1220 \mathrm{~m}$ e atualmente, o mesmo ponto apresenta uma largura de 630m (Figura 5). Além disso, caso fosse projetado uma área restritiva referente ao primeiro ano mencionado, tendo aproximadamente $820.000 \mathrm{~m}^{2}$, já com os ajustes referentes às margens, esta poderia ficar significativamente comprometida, já que, segundo o mapeamento realizado por Santos (2006), em apenas dois anos (1974-1976) foi erodida uma área equivalente a $850.000 \mathrm{~m}^{2}$.

Figura 5: Imagem ALOS 2008 com as margens e ilhas digitalizadas da foz em 1954 e a diferença das larguras de um mesmo ponto entre as duas épocas, indicando intensa dinâmica e variação morfológica

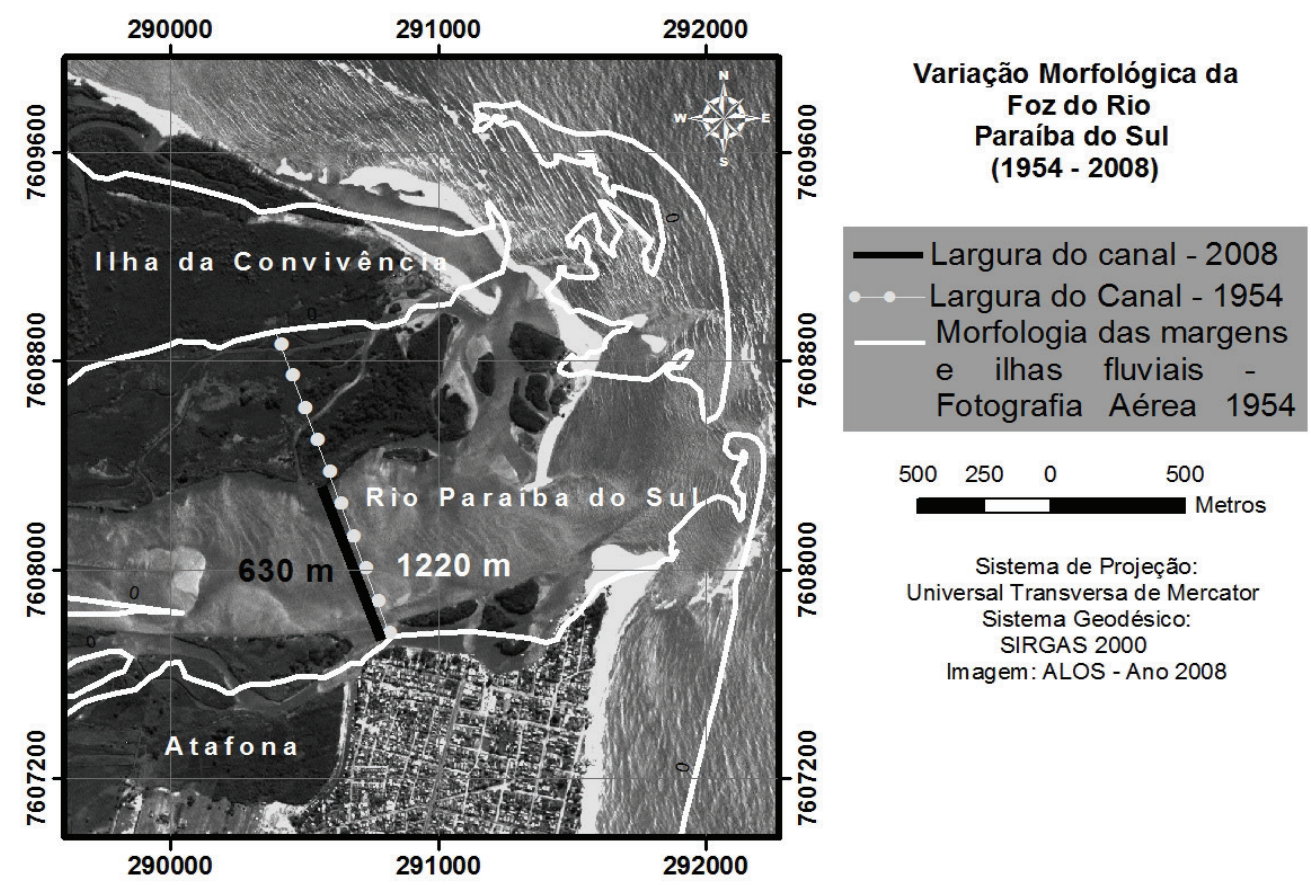

Elaboração dos autores.

Logo, caso tal discussão fosse levada a diante pelos gestores, poderia ser utilizado um critério baseado nas taxas médias anuais de erosão, como é o caso do estado americano da Carolina do Norte, que estabelece regras de construção de orla a partir de taxas médias anuais de erosão, conforme apontou Muehe (2004). No caso da presente área, a taxa anal de erosão mapeada foi de 4,6 m/ano. Cabe ressaltar que esta taxa está associada a um monitoramento topobatimétrico realizado entre 2005 e 2010. Já Santos (2006), a partir de fotografias áreas entre o ano de 1954 e 2000, encontrou uma taxa de $3,2 \mathrm{~m} / \mathrm{ano}$.
Ainda assim, a discussão relativa às áreas de não-edificação ou de usos restritivos no âmbito no plano de gestão da orla marítima, aparece apenas como uma sugestão de diretriz. Tal proposta não é considerada no real escopo do programa, sobretudo em função da pressão dos agentes imobiliários. Apesar da desconsideração do assunto, uma forma de tentar viabilizar áreas de não-edificação ou de uso restritivo, trata-se da procura por outros instrumentos de gestão a que venham viabilizar tal ação.

A Resolução Conama n.303 de 2002, que dispõe sobre parâmetros e limites de Áreas de Preser- 
vação Permanente (APPs), aparece como um bom instrumento que pode ser utilizado na gestão de orla marítima, uma vez que confere diretrizes específicas à ambientes costeiros como as dunas, restingas, brejos, manguezais e lagoas. Particularmente sobre a área de estudo, as restingas e os manguezais aparecem como o ambiente ou ecossistema mais evidente na orla marítima.

\section{UNIDADES DE PAISAGEM E TIPOLOGIAS DE ORLAS}

A caracterização da morfodinâmica costeira e o mapeamento do campo de dunas permitiram a individualização de três unidades de paisagem distintas. A primeira associada a uma extensa planície de cristas de praia e pequenas dunas sobre estas (Beach Foredune Ridges), fixadas por vegetação rasteira, na qual está associada à tendência de progradação da linha de costa (Figura 6A). A segunda, associada a dunas transgressivas (Figura 6B), cujo desenvolvimento está relacionado ao comportamento erosivo da linha de costa. E ainda, entre essas duas unidades, foi mapeada uma terceira cuja caracterização é atribuída ao fato de se tratar de uma área de transição entre os outros dois domínios. Tal caracterização encontra-se descrito em detalhes em Fernandez et al. (2008) e Rocha (2009).

Figura 6: 6A - Unidade de Paisagem referente às Dunas Frontais sob Cristas de Praia (Beach Foredune Ridges). 6B - Unidade de Paisagem de Dunas Transgressivas
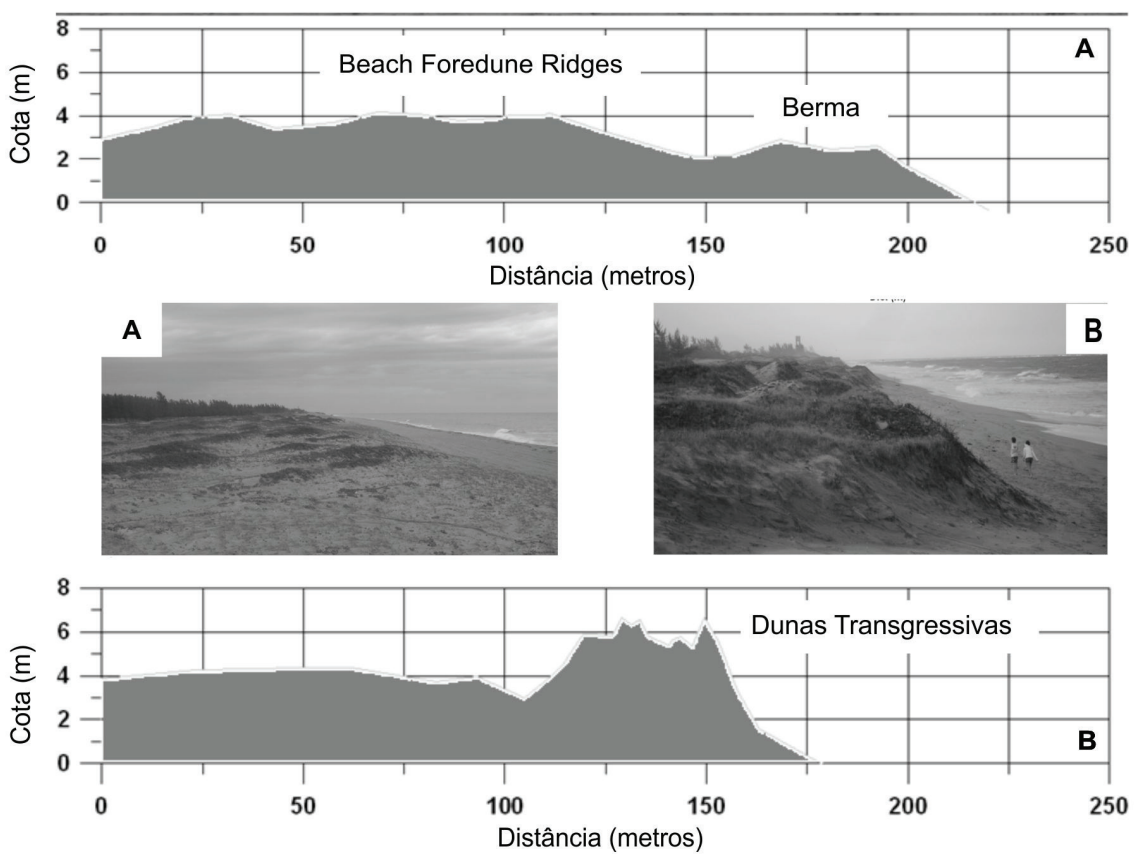

Fonte: ROCHA, T.B. Trabalho de campo. Abril de 2010.

Seguindo para a classificação de tipologias, a partir de avaliação visual, o litoral estudado está classificado inteiramente como exposto. Considerando que este litoral tem áreas em progradação, em estabilidade e em erosão, a utilização apenas deste critério não aparece como um bom indicador para avaliar a vulnerabilidade física da orla.

Neste sentido, avaliar o comportamento da linha de costa através dos Geoindicadores, diagnosticando orlas como erosivas, estáveis ou acrescionais aparece como alternativa, sobretudo se a finalidade está associada ao mapeamento da vulnerabilidade da orla. Geralmente tal avaliação é realizada por meio de longos monitoramentos e/ou utilizando sensoriamento remoto. Entretanto, tais métodos aparecem como pouco viáveis para serem realizados para um contexto de 
gestão, podendo consumir algum tempo (como alguns anos), corpo técnico muito especializado e ter um custo elevado, sobretudo quando há poucas informações e pesquisas realizadas numa determinada área.

Conforme mostra a tabela 2, a aplicação de geoindicadores estabelecidos por Bush et al. (1999) para conferir esse estado ambiental mostrou-se positiva quando comparado com os resultados obtidos pelo monitoramento morfodinâmico, realizado entre 2005 e 2010 através de topobatimetria, cuja metodologia é indicada em Muehe et al. (2003) e Fernandez et al. (2006). Ainda assim, algumas limitações foram encontradas. A visualização de indicadores torna-se prejudicada quando aplicadas a praias alteradas e com presença de significativa infra-estrutura urbana e paisagística, conforme foi verificado no ponto 10 .
Outro fato encontrado refere-se à relação da escala temporal do método com o processo. $\mathrm{O}$ ponto 1 e 2, os mais próximos à foz, apresentam muita instabilidade morfológica em função da coexistência da hidrodinâmica fluvial e oceanográfica. Tal fato é corroborado pelo monitoramento topobatimétrico e também pelos valores de instabilidade obtidos a partir do desvio padrão das larguras das praias levantadas ao longo desses anos, segundo os critérios de Muehe e Vallentini (1998). De acordo com a mesma tabela, os pontos 1 e 2 apresentaram os maiores valores de desvio padrão (tabela 2). Nesse sentido, baseado no tempo de monitoramento realizado, recomenda-se uma atualização dos indicadores de no máximo dois anos, com a diminuição desse intervalo para as áreas mais próximas à foz.

Tabela 2: Quadro síntese com os Geoindicadores mapeados, respectivos estados ambientais comparados com o comportamento e características morfodinâmicas.

\begin{tabular}{|c|c|c|c|c|}
\hline $\begin{array}{l}\text { Pontos de Moni- } \\
\text { toramento }\end{array}$ & $\begin{array}{l}\text { Geoindicadores } \\
\text { Mapeados }\end{array}$ & $\begin{array}{c}\text { Estado Mapeado } \\
\text { (SOE - Geoindicadores) }\end{array}$ & $\begin{array}{c}\text { Monitoramento } \\
\text { Tobatimétrico } \\
2005-2010\end{array}$ & $\begin{array}{c}\text { Instabilidade } \\
\text { (Desvio Padrão / } \\
\text { Largura da Praia) }\end{array}$ \\
\hline P 1 & 13,16 & * Ponto muito instável & $\begin{array}{c}\text { Erosão /instabili- } \\
\text { dade }\end{array}$ & $25,36 \mathrm{~m}$ \\
\hline P 2 & $2,4,6,7,10,11$ & Erosão Severa & $\begin{array}{c}\text { Erosão /instabili- } \\
\text { dade }\end{array}$ & $19,88 \mathrm{~m}$ \\
\hline P 3 & $2,4,6,7,10,11$ & Erosão Severa & Erosão & $14,57 \mathrm{~m}$ \\
\hline P 4 & $2,4,6,7,10,11$ & Erosão Severa & Erosão & $14,91 \mathrm{~m}$ \\
\hline P 5 & $2,4,6,7,8,10,11$ & Erosão Severa & Erosão & $13,77 \mathrm{~m}$ \\
\hline P 6 & $8,11,13$ & Erosão & Estabilidade & $5,18 \mathrm{~m}$ \\
\hline P 7 & $14,16,17,18$ & Acresção / estabilidade & Acresção & $4,71 \mathrm{~m}$ \\
\hline P 8 & $14,16,17,18$ & Acresção / estabilidade & Acresção & $8,21 \mathrm{~m}$ \\
\hline P 9 & $14,16,17,18$ & Acresção /estabilidade & Acresção & $12,71 \mathrm{~m}$ \\
\hline P 10 & 16,17 & $\begin{array}{l}\text { Acresção / estabilidade } \\
\text { * Praia modificada }\end{array}$ & Acresção & $8,54 \mathrm{~m}$ \\
\hline
\end{tabular}

Elaboração dos autores.

Desta forma, a partir das três unidades de paisagem foram individualizados quatro setores de escala maior que as unidades, e classificadas de acordo com a proposta de classificação visual de exposição a ondas, e pelos 
Geoindicadores. A unidade da foz e dunas transgressivas foi setorizada em outras duas áreas, sendo uma de domínio mais efetivo da dinâmica característica de desembocadura fluvial e sem presença efetiva de dunas; e uma segunda sendo classificada como de grande instabilidade morfodinâmica e tendência à erosão severa, e ainda considerando a informação de ser uma orla exposta, conforme mostra a figura 7.

A Unidade de Paisagem de Dunas Frontais sobre Cristas de Praia obteve trechos de orla classifi- cada como orla Exposta com tendência à estabilidade ou progradação, que tem como pontos de controle morfodinâmico os pontos P7, P8, P9 e P10. Entre esta Unidade e a primeira, também foi estabelecida uma Unidade de Transição, caracterizada pelo P6. Este ponto, segundo o monitoramento morfodinâmico, apresenta as características mais estáveis da costa, embora nos últimos dois anos tenha apresentado sutis características erosivas (Figura 7).

Figura 7. Esquema das Unidades de Paisagem e respectivos setores de tipologias de orla no delta meridional do rio Paraíba do Sul.

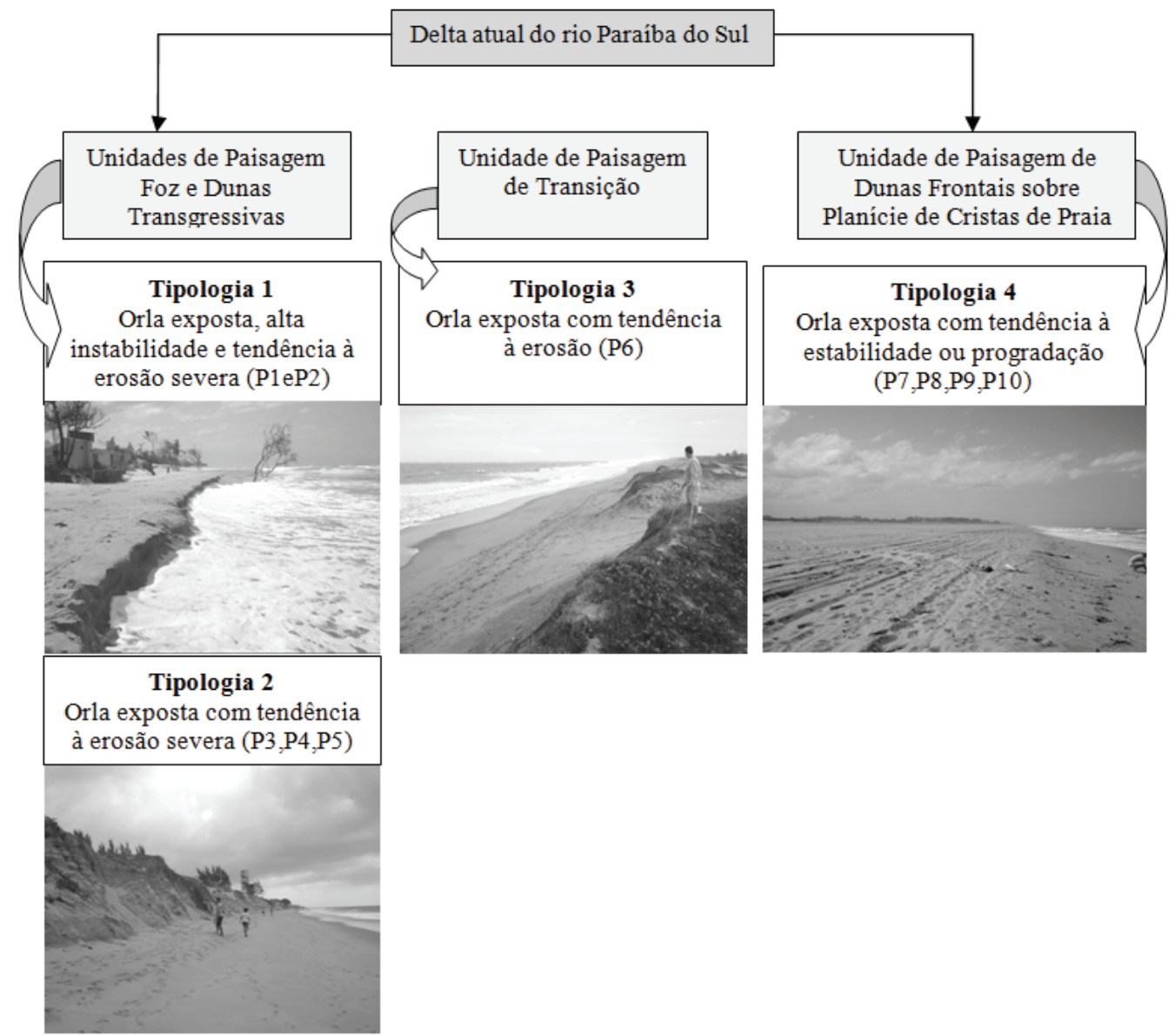

Fonte: ROCHA, T.B. Trabalho de campo. Abril de 2010.

\section{DISCUSSÕES}

A aplicação prática dos critérios físicos e morfodinâmicos para a gestão de orla marítima, sobretudo para a obtenção de um Diagnóstico, indicaram algumas fragilidades e a necessidade de adaptações às características geomorfológicas da orla (Tabela 3). O critério para o mapeamento da faixa de orla marítima foi estabelecido considerando as características mais evidentes da morfologia costeira local, neste caso, os limites da praia. $\mathrm{Na}$ verdade, dentre as várias possibilidades de limites de orla, somente a linha de preamar não deveria ser recomendada, uma vez que ela resultará em uma área reduzida de orla marítima e pode ser confundida com os terrenos 
de marinha. Além disso, a utilização de aplicativos de geoprocessamento mostrou-se prática e precisa na obtenção do objetivo e respectivo produto.

Especificamente para a síntese de áreas de uso restritivo em costa associada à desembocadura fluvial, o critério definido em função da largura da foz indicou pouca aplicabilidade. Desta forma, o critério sugerido a partir de médias de taxas de erosão anual aparece como alternativa. Ainda assim, apesar da pouca viabilidade conferida à implementação das faixas de não-edificação ou de uso restritivo nos planos para a gestão de orla marítima, outros instrumentos de gestão oferecem alguma possibilidade, como é o caso da legislação referente ás Áreas de Preservação Permanente (APPs), sobretudo quando estiver atrelado ao Plano Diretor municipal.

Tabela 3: Quadro síntese dos produtos para o Diagnóstico do Projeto Orla, baseado nos critérios morfodinâmicos e fisiográficos, com as respectivas sugestões de adaptação e complementação.

\begin{tabular}{ccr}
\hline PRODUTO & VOLUME(PROJETO & SUGESTÃO DE \\
(PROJ. ORLA) & ORLA) & COMPLEMENTAÇÃO \\
\hline
\end{tabular}

\author{
Delimitação \\ da faixa de orla \\ marítima
}
Delimitação
de faixas de restrição à ocupação
Volume "Subsídios do Projeto Orla"
(MMA, 2004)

\author{
para Gestão Integrada da \\ Orla" \\ (MMA, 2002)
}

- Utilização dos critérios de delimitação considerando as características fisiográficas locais;

- Utilização de aplicativos de SIG, como base ao mapeamento georreferenciado

- Utilização do critério de taxas médias anuais de erosão;

- Associação com outros instrumentos de gestão como o Plano

Diretor e a Legislação de APPs

- Escolha do critério que melhor

Mapeamento de Unidades de Paisagem

Classificação de Tipologias de Orla (referente à vulnerabilidade física)
Volume "Fundamentos para Gestão Integrada da Orla" (MMA, 2002)

Volume "Subsídios do Projeto Orla"e Fundamentos para

Gestão Integrada da Orla" (MMA, 2002 e 2004) caracteriza a paisagem local (físico ou de ocupação);
- Utilização de Geoindicadores relativos à tendência de comportamento da linha de costa;

- Associação de monitoramentos de dinâmica praial de curto á médio prazo. 
A definição das unidades de paisagem obtida pelo critério morfodinâmico e fisiográfico, assim como o posterior mapeamento das tipologias de orla dos setores na área do presente trabalho, teriam condições de traçar objetivos e nortear planos e ações condizentes com os distintos setores caracterizados. Uma associação entre essas condições ambientais ao mapeamento das condições e do padrão de ocupação, por exemplo, permitiria o direcionamento de ações que seriam de cunho restritivo e/ou preventivo. Logo, o que de fato aparece como deficiente não é a metodologia baseada no Diagnóstico Paisagístico, mas os métodos e indicadores respectivos.

A tipologia obtida a partir do grau de exposição de ondas mostrou-se insuficiente em termos de informação. Nesse sentido, uma tipologia baseada no comportamento da linha de costa pode fornecer uma avaliação mais eficiente em termos de vulnerabilidade. A aplicação de geoindicadores para conferir esse estado ambiental (SOE) mostrou-se positiva quando comparado com os resultados obtidos pelo monitoramento morfodinâmico, embora necessite de estudos pontuais para cada um dos indicadores e de quantificação para a avaliação da SOE. Ainda assim, esta alternativa metodológica apresenta-se coerente com a metodologia do Diagnóstico Paisagístico do Programa, além de bastante viável em função do baixo-custo e da rápida e fácil aplicação. Porém, pelo diagnóstico temporal pouco eficiente, desconsiderar monitoramentos pode ser comprometedor para áreas com aspectos morfodinâmicos complexos.

\section{CONSIDERAÇÕES FINAIS}

Apesar da complexidade físico-ambiental da respectiva área de estudo, destacada pela severa erosão próxima à foz, presume-se que as mencionadas questões e critérios sugeridos possam ser aplicados nas demais orlas marítimas caracterizadas por praias arenosas que eventualmente possuam desembocaduras fluviais. Tais produtos, aliados ao cuidadoso estudo e interpretação dos respectivos volumes do Projeto Orla pelos gestores, devem auxiliar a instrumentalização e o diagnóstico da orla marítima e, conseqüentemente, o direcionamento de ações que sejam de cunho restritivo e/ou preventivo.
Cabe ressaltar que embora o Projeto Orla detenha um forte apelo urbanístico, não se deve ignorar a sua característica ambiental, seja para caracterização, preservação e mapeamento de áreas de risco ou vulnerabilidade. Portanto, espera-se que o presente trabalho tenha contribuído para o fortalecimento deste importante instrumento, com a análise e discussão, não somente de suas limitações como de suas potencialidades.

\section{REFERÊNCIAS BIBLIOGRÁFICAS}

ARAÚJO, T. C. M.; SILVA, V. B.; CARVALHO, J. R. Classificação da tipologia da orla da cidade de OlindaPE: Delimitação e Caracterização. Revista Brasileira de Geomorfologia, n. 1, 2006.

BASTOS, A.C. Análise morfodinâmica e caracterização dos processos erosivos ao longo do litoral norte fluminense, entre Cabiúnas e Atafona. 1997. Dissertação (Mestrado em Geologia e Geofísica Marinha), Instituto de Geociências, Universidade Federal Fluminense, Niterói, Rio de Janeiro, 1997.

BERGER, A.R. Assessing rapid environmental changes using geoindicators. Environmental Geology, v.32, p. 36-44, 1997.

BRASIL. Lei n. 7.661, de 16 de maio de 1988. Institui o Plano Nacional de Gerenciamento Costeiro e dá outras providências. Disponível em: $<\mathrm{http}: / / \mathrm{www}$. planalto.gov.br/ccivil_03/leis/17661.htm> Acessado em: 23 ago.2012. 1988.

BRASIL. Decreto n. 5.300 de 7 de dezembro de 2004. Institui o Plano Nacional de Gerenciamento Costeiro (PNGC), dispõe sobre regra de uso e ocupação da zona costeira e estabelece critérios de gestão de orla marítima. Disponível em: <http://www.planalto.gov. br/ccivil_03/_ato2004-2006/2004/decreto/D5300. $\mathrm{htm}>$ Acessado em: 23 ago.2012. 2004.

BUSH, D. M.; NEAL, W.J.; YOUNG, R.S; PILKEY, O.H. Utilization of geoindicators for rapid assessment of coastal -hazard risk and mitigation. Ocean and Coastal Management, v.42, p. 647-670, 1999. 
DIAS, G. T. M. O complexo deltáico do Rio Paraíba do Sul. In: SIMPÓSIO DO QUATERNÁRIO, 4,1981, Rio de Janeiro. Anais... Rio de Janeiro: CTCQ/SBG, 1981. p 58-88.

DOMINGUEZ, J. M. L.; BITENCOURT,A.C.S.P.; MARTIN, L. O papel da deriva litorânea de sedimentos arenosos na construção das planícies costeiras associadas a desembocaduras dos rio São Francisco, Jequitinhonha, Doce e Paraíba do Sul. Revista Brasileira de Geociências, v. 13, n.2, p.93-105, 1983.

FERNANDEZ, G. B.; ROCHA, T.B.; PEREIRA, T.G.; FIGUEREDO, J.R. A.G. Morfologia e dinâmica de praia entre Atafona e Grussaí, litoral norte do estado do Rio de Janeiro. In: SIMPÓSIO NACIONAL DE GEOMORFOLOGIA,6., 2006, Goiania. Anais... Goiania, 2006. CD-ROM.

FERNANDEZ, G. B.; ROCHA, T.B.; PEREIRA, T.G. VASCONCELOS, S. C. Modelo Morfológico da Origem e Evolução das Dunas na Foz do Rio Paraíba do Sul, RJ. In: SIMPÓSIO NACIONAL DE GEOMORFOLOGIA, 7, 2008, Belo Horizonte. Anais... Belo Horizonte, 2008.

MMA/SQA; MP/SPU. Projeto Orla: Fundamentos para Gestão Integrada. Ministério do Meio Ambiente e Ministério do Planejamento, Orçamento e Gestão. Brasília, DF, 2002.

MMA/SQA; MP/SQU. Projeto Orla: Subsídios para um Projeto de Gestão. Ministério do Meio Ambiente e Ministério do Planejamento, Orçamento e Gestão. Brasília, DF, 2004.

MMA/SQA; MP/SQU. Projeto Orla: Manual de Gestão. Ministério do Meio Ambiente e Ministério do Planejamento, Orçamento e Gestão. Brasília, DF, 2006.

MUEHE, D. Critérios morfodinâmicos para o estabelecimento de limites da orla costeira para fins de gerenciamento. Revista Brasileira de Geomorfologia, v. 2 n. 1, p. 35-44, 2001.
. Definição de limites e tipologias de orla sob os aspectos morfodinâmicos e evolutivos. In: MMA/ SQA; MP/SQU. Projeto Orla: Subsídios para um projeto de gestão. Brasília, DF, p. 13-32, 2004.

MUEHE, D.; ROSO, R.H.; SAVI, D.C. Avaliação do Nível do Mar como Datum Vertical para Amarração de Perfis de Praia. Revista Brasileira de Geomorfologia, n.1, p 53-57, 2003.

MUEHE, D.; VALENTINI, E. O Litoral do Estado do Rio de Janeiro: Uma Caracterização Físico-Ambiental. Rio de Janeiro: FEMAR, 1998.

OTVOS, E.G. Beach ridges: definitions and significance. Geomorphology, v. 32, p. 83-108, 2000.

SÃO JOÃO DA BARRA (Prefeitura municipal). Lei $N^{o}$ 050/2006, de 26 de dezembro de 2006. Plano Diretor Municipal. 2006.

ROCHA, T. B. Morfodinâmica Costeira e Gestão de Orla Marítima Em Costa Sob Influência Fluvial: Borda meridional do atual delta do Rio Paraíba do Sul (RJ). 2009. Dissertação (Mestrado em Geografia). Programa de Pós-Graduação em Geografia. Universidade Federal Fluminense, Niterói, Rio de Janeiro, 2009.

SANTOS, R. A. Processos de Erosão e Progradação entre as praias de Atafona e Grussai - RJ. 2006. Monografia de Graduação, Curso de Geografia. Universidade Federal Fluminense, Niterói, Rio de Janeiro, 2006.

\section{AGRADECIMENTOS}

O trabalho foi realizado com apoio financeiro da CAPES e CNPq-Brasil. 